See Article page 137.

\section{Commentary: Too much of a good thing}

\author{
Jason W. Greenberg, MD, and \\ David L. S. Morales, MD
}

Trezzi and colleagues ${ }^{1}$ report their experience with "dynamic" superior vena cava (SVC) occlusion in a patient with a HeartMate 3 right ventricular assist device (RVAD) in place. The authors report the case of a previously healthy patient with viral myocarditis complicated by cardiogenic shock and presumed unrecoverable cardiac function, who ultimately required the placement of biventricular assist devices as a bridge to transplant. Shortly following RVAD placement, the patient was found to have an acute increase in central venous pressure. Workup with echocardiography, cardiac catheterization, and angiography revealed an area of stenosis near the SVC-right atrial junction. The RVAD cannula itself-placed into the right atrium, in accordance with the implantation techniques of previous reports - was first ruled out as the cause of stenosis. ${ }^{2,3}$ Instead, it was proposed that a "suction effect" from the RVAD during periods of relative "mismatch" between the left ventricular assist device (LVAD) and RVAD outflow was the etiology. By decreasing the rate of the RVAD, complete resolution of SVC stenosis and elevated central pressure were achieved. The authors found that the ideal RVAD flow rate for prevention of atrial "suctioning" in their patient was approximately $75 \%$ of the systemic flow rate.

\footnotetext{
From the Department of Cardiovascular Surgery, Cincinnati Children's Hospital Medical Center, Cincinnati, Ohio.

Disclosures: Dr Morales is a consultant, instructor, and advisor to Berlin Heart; a proctor, consultant, instructor, and national principal investigator for the 50/50 trial for SynCardia; a consultant within the HeartWare Division of Medtronic; and a consultant within the Thoratec Division of Abbott. Dr Greenberg reported no conflicts of interest.

The Journal policy requires editors and reviewers to disclose conflicts of interest and to decline handling or reviewing manuscripts for which they may have a conflict of interest. The editors and reviewers of this article have no conflicts of interest.

Received for publication July 24, 2021; revisions received July 24, 2021; accepted for publication July 30, 2021; available ahead of print Aug 4, 2021.

Address for reprints: Jason W. Greenberg, MD, Division of Congenital Cardiothoracic Surgery, Heart Institute, Cincinnati Children's Hospital Medical Center, University of Cincinnati College of Medicine, 333 Burnet Ave, Cincinnati, OH 45229 (E-mail: jasongreenbergmd@gmail.com).

JTCVS Techniques 2021;9:141-2

2666-2507

Copyright (C) 2021 The Author(s). Published by Elsevier Inc. on behalf of The American Association for Thoracic Surgery. This is an open access article under the CC BY-NC-ND license (http://creativecommons.org/licenses/by-nc-nd/4.0/).

https://doi.org/10.1016/j.xjtc.2021.07.030
}

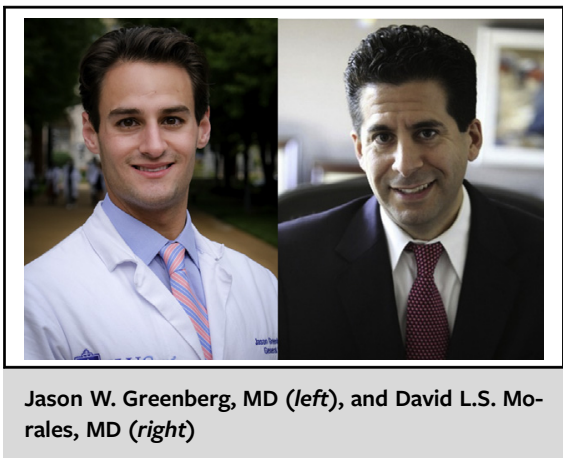

CENTRAL MESSAGE

The optimal degree of pressure and volume "offloading" of the right heart in the setting of dual ventricular assist device support requires further study.

Trezzi and colleagues ${ }^{1}$ provide a commendable example of applied clinical reasoning and ingenious problemsolving, but while undoubtedly novel in its description and approach, we must be careful not to apply too broadly the conclusions from this case report. First, the physiologic and anatomic considerations of RVADs placed in the right atrium differ from those of the ventricle, so the diagnosis and reduction in flow rate described here may not apply to ventricularly placed RVADs. Similarly, the "suction effect" described by the authors is simply a theory; more specific hemodynamic information regarding the flow dynamics of atrial RVADs dependent on LVAD outflow requires further examination. Future studies should seek to incorporate basic research to answer the remaining physiologic and hemodynamic questions, whereas including a greater number of patients in future reports will help to more fully elucidate this clinical problem and to confirm the ideal RVAD flow rate.

There is not a clear understanding of how much decompression of the right atrium-a "good thing"-is ideal when attempting to balance a paracorporeal continuousflow RVAD via a transjugular cannula with an intracorporeal LVAD. One may feel that a greater level of right-sided decompression is better in all patients, but as this case illustrates, that is not always the case. Until the hemodynamic interactions between RVADs and LVADs are better understood and have undergone more scientific scrutiny, we must rely on the resourcefulness and critical thinking exemplified by Trezzi and colleagues to solve such clinical problems. Clearly, there can sometimes be too much of a good thing. 


\section{References}

1. Trezzi M, Brancaccio G, Filippelli S, Esposito C, Iacobelli R, Guccione P, et al. Dynamic superior vena cava occlusion with an atrial implanted pediatric right ventricular assist device. J Thorac Cardiovasc Surg Tech. 2021;9:137-40
2. Lavee J, Mulzer J, Krabatsch T, Marasco S, McGiffin D, Garbade J, et al. An international multicenter experience of biventricular support with HeartMate 3 ventricular assist systems. J Heart Lung Transplant. 2018;37:1399-402.

3. Tran HA, Pollema TL, Silva Enciso J, Greenberg BH, Barnard DD, Adler ED, et al. Durable biventricular support using right atrial placement of the HeartWare HVAD. ASAIO J. 2018;64:323-7. 